\title{
EXCREÇÃO DE CREATININA NO PERfODO DE VINTE E QUATRO HORAS, EM CRIANÇAS DE CINCO A ONZE ANOS DE IDADE
}

\author{
Ignez Salas MARTINS *
}

\begin{abstract}
\begin{tabular}{l|l|} 
RSPU-B/204 \\
\hline
\end{tabular}
MaRTiNs, I. S. - Excreção de creatinina no periodo de vinte e quatro horas, em crianças de cinco a onze anos de idade. Rev. Saúde públ., S. Paulo, 8: $63-6,1974$.

RESUMO: Estudou-se o modo de excreção da creatinina em um periodo de 24 horas em crianças de 5 a 11 anos. Dentro desse perfodo a excrecão de creatinina foi constante, não apresentando ritmo cireadiano.
\end{abstract}

UNITERMos: Creatinina*; Ritmo circadiano*.

\section{N T RODU C A O}

O estudo do modo de excreção da creatinina em 24 horas, ou ritmo circadiano reveste-se de importância por ser este constituinte urinário, muito usado como referência de outras substâncias da urina em razōes do seguinte tipo:

$$
\text { constituinte } \mathrm{x} \text { ( } \mathrm{mg} \text { ou } \mathrm{uM})
$$

creatinina ( $\mathrm{mg}$ ou $\mathrm{uM}$ )

0 uso desse índice pressupõe uma constância na excreção da creatinina que é, até hoje, assunto controvertido.

Em 1905, Folis ${ }^{4}$ afirmou que a excreção da creatinina é constante durante longo período de tempo. Estudos posteriores, entretanto, ora vêm de encontro às afirmações de Folin, ora as contradizem.
Por essa razão, o objetivo deste trabalho é constatar se a creatinina apresenta rítmo circadiano.

\section{CASUISTICA E METODOS}

Foram colhidas amostras de micção espontânea, de oito crianças ( 3 do sexo feminino e 5 do sexo masculino) entre 5 e 11 anos, num período de 24 horas. Essas crianças pertencem a um dos lares do Orfanato "Reino da Garotada" localizado no municipio de Poá. Não foram submetidos a qualquer restrição às suas atividades normais ou à dieta que foi comum a todas por pertencerem ao mesmo lar.

0 métodä́ usado para a dosagem da creatinina foi o de Folin (utilizando a reação de Jaffé) modificado **.

- Do Departamento de Nutrição da Faculdade de Saúde Pública da USP - Av. Dr. Arnaldo, 715 - São Paulo, SP - Brasil.

** A $0,1 \mathrm{ml}$ de urina diluida 10 vezes, juntam-se $2 \mathrm{ml}$ de ácido picrico e em seguida $0,15 \mathrm{ml}$ de $\mathrm{NaOH}$ a $10 \%$. Depois de $15 \mathrm{~min}$ de repouso para estabilização da cor, juntam-se 7,7 $\mathrm{ml}$ de $\mathrm{H}_{2} \mathrm{O}$ e lê-se em colorimetro Coleman (515 mu). 
MARTINS, J. S. - Excreção de creatinina no periodo de vinte e quatro horas, em crianças de cinco a onze anos de idade. Rev. Saúde públ., S. Paulo, 8: 63-6, 1974.

\section{RESULTA DOS}

Fazendo-se um gráfico da excreção acumulada de creatinina em função do tempo, para cada indivíduo (Figura) a distribuição dos pontos sugerem uma relação linear indicando, portanto, constância na excreção da creatinina em qualquer período do dia.

\section{COMENTARIOS}

Clark et al. ${ }^{2}$ (1951) referem que amostras colhidas ao acaso têm média bem próxima daquelas colhidas em 24 horas. VESTERGAARD et al. ${ }^{16}$ (1958) estudando a excreção urinária de creatinina em 18 indivíduos, encontraram relativa constância em alguns deles, e grande variabilidade em outros. Plough \& Conzola. ZIO ${ }^{12}$ (1959) em 10 casos obtiveram um limite de confiança muito grande na variação da creatinina excretada. Recomendam investigação em amostras maiores. colhendo-se a urina de indivíduos em jejum ou entre o café da manhã e o almoço. Hegested e col. ${ }^{7}$ (1959) em amostras colhidas de 2 em 2 horas, encontraram desvio padrão muito grande no estudo de quatro casos. Powel et al. ${ }^{13}$ (1961) analisando a ciclagem do nitrogênio e da creatinina encontraram variação semelhante entre ambos, o que tornou viável o uso da razão nitrogênio total/creatinina. KoIshi ${ }^{9}$ (1962) em três indivíduos, encontrou excreção média maior no periodo diurno. HALAUER et al. ${ }^{5}$ (1966) tomando amostras de duas em duas $h$ durante o período diurno, e de $12 \mathrm{~h}$ durante o noturno, encontraram constância na excreção diurna; porém a excreção média noturna foi significantemente menor. PAterson ${ }^{11}$ (1967) no estudo de 8 casos encontrou uma variabilidade muito grande, e por isso coloca em dúvida a validade do uso da creatinina como referência de outros constituintes urinários. EDWARDS et al. ${ }^{8}$ (1969) verificaram variação considerável na excreção urinária de creatinina que não podia sẹ atribuída nem a erros analíticos, nem a mudança de atividade física ou dieta. Chataway ${ }^{1}$ (1969) concluiu que amostras colhidas ao acaso podem não ser representativas da excreção de $24 \mathrm{~h}$ para alguns indivíduos, porquanto a excreção da creatinina depende de outros fatores além da massa muscular, como por exemplo; balanço hormonal. Hogden et al. ${ }^{8}$ (1967) estudaram 14 grupos de ovelhas, colhendo amostras de 6,12 e 24 horas, durante quatro dias. Encontraram desvio padrão menor nos intervalos mais longos, porém, não foi significante a diferença nas quantidades excretadas durante os períodos de 6 horas. HALE et al. ${ }^{6}$ (1967) obtiveram resultados semelhantes em amostras de 4 horas colhidas durante o período diurno e noturno. Scotr \& HurLey ${ }^{14}$ (1968) observaram a variação da excreção da creatinina durante o estudo do "turnover" de umą proteína radioidada em que o radioisótopo catabolisado era eliminado pela urina. A constância da razão radioisótopo urinário/ radioisótopo do plasma foi tida como indicativa de uma coleta acurada. A variabilidade na excreção da creatinina foi muito grande, e, como Paterson, esses investigadores põem em dúvida a validade de seu uso como referência de outros constituintes urinários. PAsternaK \& KULBACK ${ }^{10}$ (1971) apenas encuntraram constância na excreção da creatinina quando os indivíduos sob investigação estiveram em jejum. Entretanto, SzADKowISKI et al. ${ }^{15}$ (1970) encontraram em 10 indivíduos, de 27 a 75 anos, uma excreção média constante durante oito dias.

No presente trabalho, como foi referido, a distribuição dos pontos (Figura) sugerem constância na excreção da creatinina.

\section{CON C L U S O}

Em amostras de micção espontânea em oito indivíduos, entre 5 e 11 anos de idade, sem restrição às suas atividades normais e dieta, a excreção da creatinina não apresentou ritmo circadiano. 
MARTINS, J. S. - Excreção de creatinina no periodo de vinte e quatro horas, em crianças de cinco a onze anos de idade. Rev. Saúde puibl., S. Paulo, 8: 63-6, 1974.

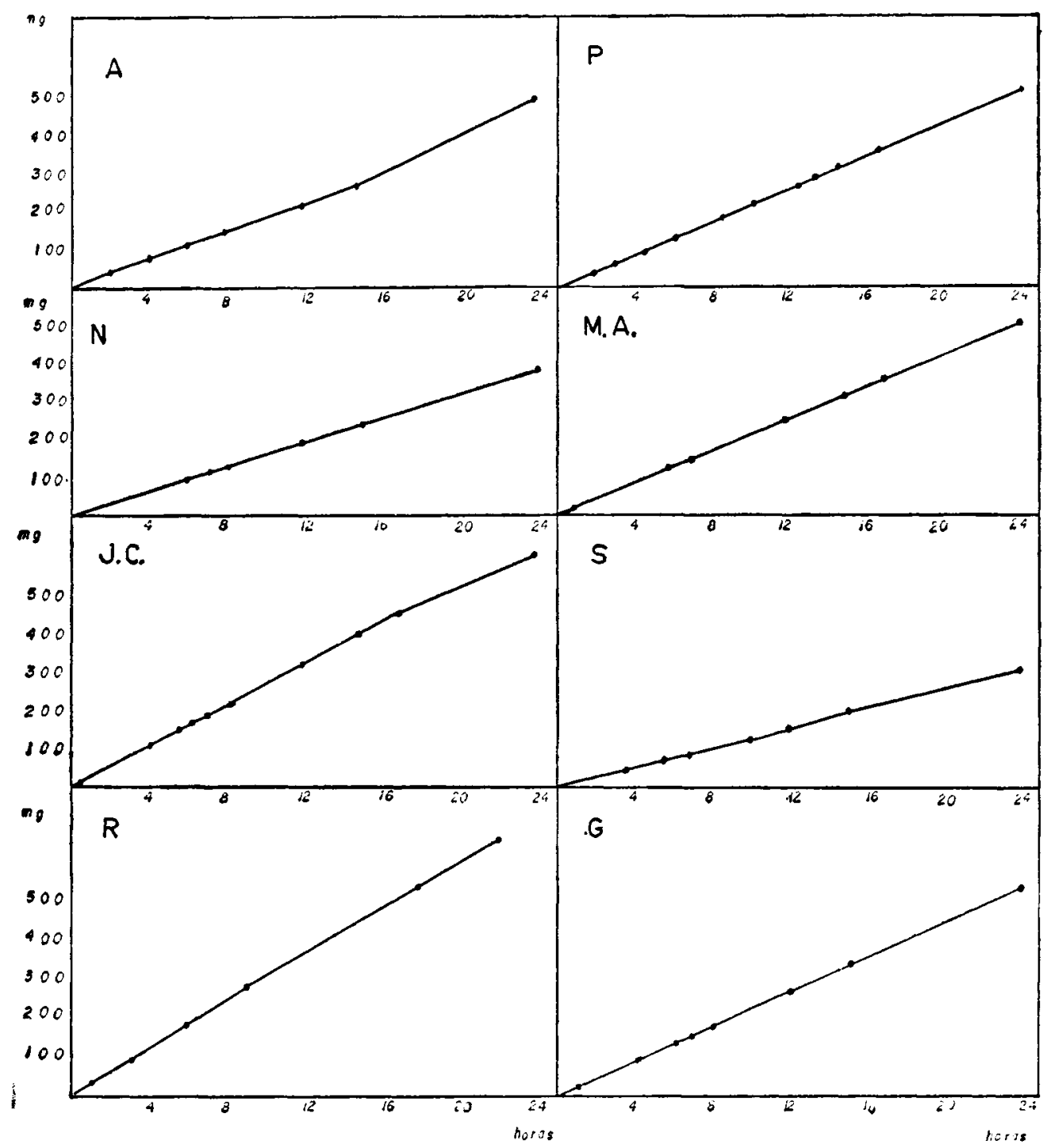

Figura - Excreção acumulada de creatinin em 24 horas em funcão do tempo em 8 individuos. 
MARTINS, J. S. - Excreção de creatinina no periodo de vinte e quatro horas, em crianças de cinco a onze anos de idade. Rev. Saúde públ., S. Paulo, 8: 63-6, 1974.

MARTINS, I. S. - [Creatinin excretion during the period of twenty-four hours in children from five to eleven years old.] Rev. Saúde públ., S. Paulo, 8: $63-6,1974$.

SUMMARY: It was studied the creatinine excretion over a period of twenty four hours in children from five to eleven years of age. During this period the creatinine excretion was constant and without circadian rhythm.

UNITERMS: Creatinine*; Circadian rhythm.

\section{REFERENCIAS BIBLIOGRAFICAS}

1. CHATTAWAY, F. W. et al. - The variability of creatinine excretion in normal subjects mental patients and pregnant women. Clin. Chim. Acta, 26 : 567-76, 1969.

2. CIAARCK Jr. L. C. et al. - Excretion of creatinine by children. Amer. J. Dis. Chil., 81: 771-3, 1951.

3. EDWARDS, O. M. et al. - Urinary creatinine excretion as an index of the completeness of 24 hour urine collections. Lancet, 2: 1165-6, 1969.

4. FOLIN apud RITCHEY, S. J. et al, Variability of creatinine excretion in preadolescent girls consuming a wide range of dietary nitrogen. Amer. $J$. clin. Nutr., 26:690-5, 1973.

5. HELAUER, W. et al. - Investigation on the constancy of creatinine excretion during short periods of urine collection. Arch. Klin. Med., 213: 113, 1966.

6. HALE, B. H. et al. - Validity of the human 17-hidroxycorticosteroid/creatínine ratio. Aerosp. Med., 38: 10958, 1967.

7. HEGSTED, D. M. et al. - Variation in riboflavin excretion. $J, N u t r ., 60$ : 581-97, 1959.

8. HOGDEN, G. D. et al. - Estimating creatinine excretion in sheep. J. Anim. Sci., 26: 586-9, 1967.

9. KoISHI, H. - A study on diurnal variation of creatinine excretion in human subjects. Osaka City Med. J., 8: 17-28, 1962 .
10. PASTERNAK, A. \& KUHLBACK, B. Diurnal variations of serum and urine creatine and creatinine. Scand. $J$. clin. Lab. invest, 27: 1-7, 1971.

11. PATERSON, N. - Relative constancy of 24 hour urine volume and 24 hour creatinine out put. Clin. Chim. Acta., 18: 57-8, 1967.

12. PLOUGH, I. C. \& CONZOLAzIO, C. F. The use of casual urine specimens in the evaluation of the excretion rates of thiamine and n-metylnicotinamide. J. Nutr., 69: 365-70, 1959.

13. POWEL, R. C. et al. - The use of nitrogen to creatinine ratios in random, urine specimens to estimate dietary protein. J. Nutr., 73: 47-51, 1961.

14. SCOTT, P. J. \& HURLEY, P. J. - Demonstration of individual variations in constancy of 24 hour urinary creatinine excretions. Clin. Chim. Acta., 21: 411-4, 1968.

15. SZADKOWISK, D. et al. - Creatinine excretion rate as a reference value for analysis of urine samples. 1 Effect of daily urine value and circadian rhythm on creatinine excretion. Zeit. Klin. Chem. Klin. Bioch, 8: 529-33, 1970 apud Nutr. Abs. Rev, 42: 170,1972 .

16. VESTERGAARD, P. et al. - Constancy of urinary creatinine excretion. $J$. Lab. clin. Med., 51: 211-8, 1958.

Recebido para publicacão em 30-11-1973. Aprovado para publicação em 21-1-1974. 